\title{
Multi-scale Forest Habitat Monitoring Using Remote Sensing Data
}

\author{
Antonia OSBERGER ${ }^{1}$, Thomas STRASSER ${ }^{1}$, Barbara RIEDLER ${ }^{1}$, Joanna ADAMCZYK ${ }^{2}$, \\ Stefan $\mathrm{LANG}^{1}$ and Lena PERNKOPF ${ }^{1}$ \\ ${ }^{1}$ Interfaculty Department of Geoinformatics - Z_GIS, \\ University of Salzburg / Austria · antonia.osberger@sbg.ac.at \\ ${ }^{2}$ SGGW, Warsaw University of Life Sciences / Poland
}

This contribution was double-blind reviewed as full paper.

\begin{abstract}
Remote sensing imagery and advanced image analysis methods show high potential for monitoring forest habitat issues. The objective of this paper is to provide ready-to-use information on forest habitats by conducting a multi-scale approach for the delineation of such, and the assessment of their conservation status on multi-spectral satellite imagery of high and very high spatial resolution, as well as LiDAR data. This information should help forest managers in the decision-making process and contribute to a sustainable management. The evaluation of the quality of forest habitats is performed on suitable indicators such as structure and composition on broad-scale for whole landscapes and on fine-scale for individual protected sites. In this context, information layers and direct habitat mapping can help to address the complex task of monitoring forest habitats and to harmonize information output.
\end{abstract}

\section{Introduction}

Satellite-based Earth observation (EO) provides powerful tools for monitoring the state and change of forest habitats over large areas. In general, EO methods are advantageous for long-term monitoring since the needs of an area-wide coverage, timely and regular updates, standardized and reproducible methods, transferability and data harmonization, as well as cost-efficiency are covered (DURO et al. 2007, VANDEN BORRE et al. 2011). Together with in-field assessments, EO-derived information supports a sustainable forest ecosystem management (LANG et al. 2013). In Europe, forest changes are primarily caused by human interference, e.g. due to forest management (forest planting and clear-cutting, removal of dead wood and undergrowth), river regulation (prevention of flooding events, change of hydrological conditions), mining, agricultural use and urbanisation. The interference affects the species composition and age structure of forests, increases the vulnerability to disturbing events (e.g. bark beetle attacks and fire outbreaks), and contributes to the loss of woody habitat and forest fragmentation.

In this paper we present approaches to monitor the quality of forest habitats on different scales with the help of EO data. The assessment is based on multi-spectral satellite imagery 
of high (HR) and very high (VHR) spatial resolution, as well as LiDAR data, and incorporates strategies for forest change analysis. The satellite data were processed using object-based image analysis (OBIA) techniques (cf. BLASCHKE 2010, LANG 2008) to detect homogenous forest patches. Forest habitat quality was then evaluated using indicators of structure and composition, which are suitable measures to approximate the biodiversity state of habitats (GEBUREK et al. 2010, STRAND et al. 2007, MARCHETTI 2004). Additional information based on spectral values was provided in an aggregated manner as 'information layers'. In general, the concept of information layers (BUCK et al. 2013) provides broadscale, area-wide information on specific habitat-relevant biophysical attributes in a standardized spatial reporting unit. We show its potential as a forest disturbance information layer, which indicates the amount of dead wood as an attribute relevant for the quality of forest habitats.

In the presented context, multi-scale forest habitat monitoring is illustrated by the use of HR satellite data for broad-scale forest disturbance analysis, and VHR data for modelling complex forest habitat systems, and habitat quality assessment on a finer scale. Broad-scale monitoring refers to large areas like whole landscapes, whereas fine-scale monitoring addresses smaller dimensions as for example individual protected sites. The scale dependent choice for HR or VHR optical data is strongly related to data volume and processing capabilities.

\section{Broad-scale Monitoring of Forest Disturbances}

An area-wide assessment of the quality of forest habitats over large areas, respectively, over whole landscapes, is a complex monitoring task. Therefore the focus is set on the share of dead wood as one of the key indicators for the assessment of health and ecological wellfunctioning of forest ecosystems (SCHUCK et al. 2004). The volume of standing (snags) or fallen wood regulates the biodiversity of forest ecosystems, in biotic and abiotic terms, by offering meso- to microhabitats for decomposition species and serving as an important part to the global carbon, nitrogen, and phosphorus cycles. On the other hand, a high amount of dead wood may also have a negative impact on ecological functioning, ecosystem services, and economic interests (PALETTO et al. 2012). In this context, the chlorophyll content can be used as an indicator for the quality of forest habitat conditions, and to find the equilibrated balance of the amount of dead wood in a forest ecosystem. Generally, the chlorophyll content is widely used to monitor forest disturbances at an early stage (MEIGS et al. 2011, ZAWILA-NIEDŹWIECKI et al. 2000).

Forest disturbance probability maps derived from EO data, which include dead wood and chlorophyll content assessment, provide reliable and timely accurate information for monitoring purposes, as well as hot spot indication. The reliability of the results strongly depends on the transparency of the adopted method and decision criteria, which is reflected by the classification process.

The approach is based on HR RapidEye images (BlackBridge, $5 \mathrm{~m}$ ground sampling distance (GSD), five optical bands: 440-850 $\mathrm{nm}$ including the red-edge band). Data integration, data analysis, and forest disturbance information layer calculation were tackled using, among others, OBIA techniques. A simple and transparent rule-set was developed for the statistical interpretation of the forest patches. Different degrees of forest disturbance 
and the existence of dead wood were obtained using vegetation indices. The indices were chosen based on stability criteria tested in different Natura 2000 sites to produce forest disturbance information layers. They include the Normalized Difference Vegetation Index (NDVI) and the Wide Dynamic Range Vegetation Index (GiTELSON 2004). Both of them enabled a delineation of disturbed forest patches, and an extraction of standing dead wood. Additionally, the Datt4 index (DATT 1998) was found to be strongly correlated with values of the chlorophyll content. Therefore it is useful for monitoring the several stages of foliage discoloration. Zonal statistics were applied on homogenous forest patches, summarizing the values based on vegetation indices by taking into account the minimization of the heterogeneity of the forest stands. Beyond that a statistical analysis considers the issue of transferability by missing atmospheric corrections of the satellite images.

The results of the forest disturbance indication were aggregated based on the values of the vegetation indices to hexagon grids with a cell size of $500 \mathrm{~m}$. We used hexagons because their geometrical properties allow a more appropriate representation of landscape patches compared to rectangular cells. The hexagonal lattice is the most similar arrangement to a circle that can be obtained with regular tessellation. Accordingly, a hexagon has a lower perimeter-area ratio, which diminishes bias related to edge and corner effects. Among these, the configuration of six adjacent hexagons located in symmetrically equivalent positions and in the same distance from each other facilitates the interpretation of interactions in vicinity, due to a simpler and more symmetric nearest neighbourhood. The visual advantages of hexagon grid maps are even more appreciated. Hexagonal grids tend to be less ambiguous than maps in a rectangular lattice (BIRCH et al. 2007, CARR et al. 1992).

To test the transferability of the method, forest disturbance layers were calculated for different mountainous Natura 2000 sites located in various bio-geographical regions in Europe. Fig. 1 shows a subset for the Natura 2000 site Ritini - Vria Forest at Pieria Ori on Pieria Mountain within the Mediterranean region in northern Greece. The degree of forest disturbance ranges from "non-disturbed coniferous forest" (value 0) to "highly disturbed coniferous forests" (value 1). The range is indicated by a colour ramp from transparent (no disturbance) over shades of grey (low to medium disturbance) to black (high disturbance). The latter reveals hotspots of coniferous forests that are in a critical state of health. The forest disturbance information can be transferred to other corresponding sites of forest habitats with comparable results (see OSBERGER \& TIEDE 2013). 


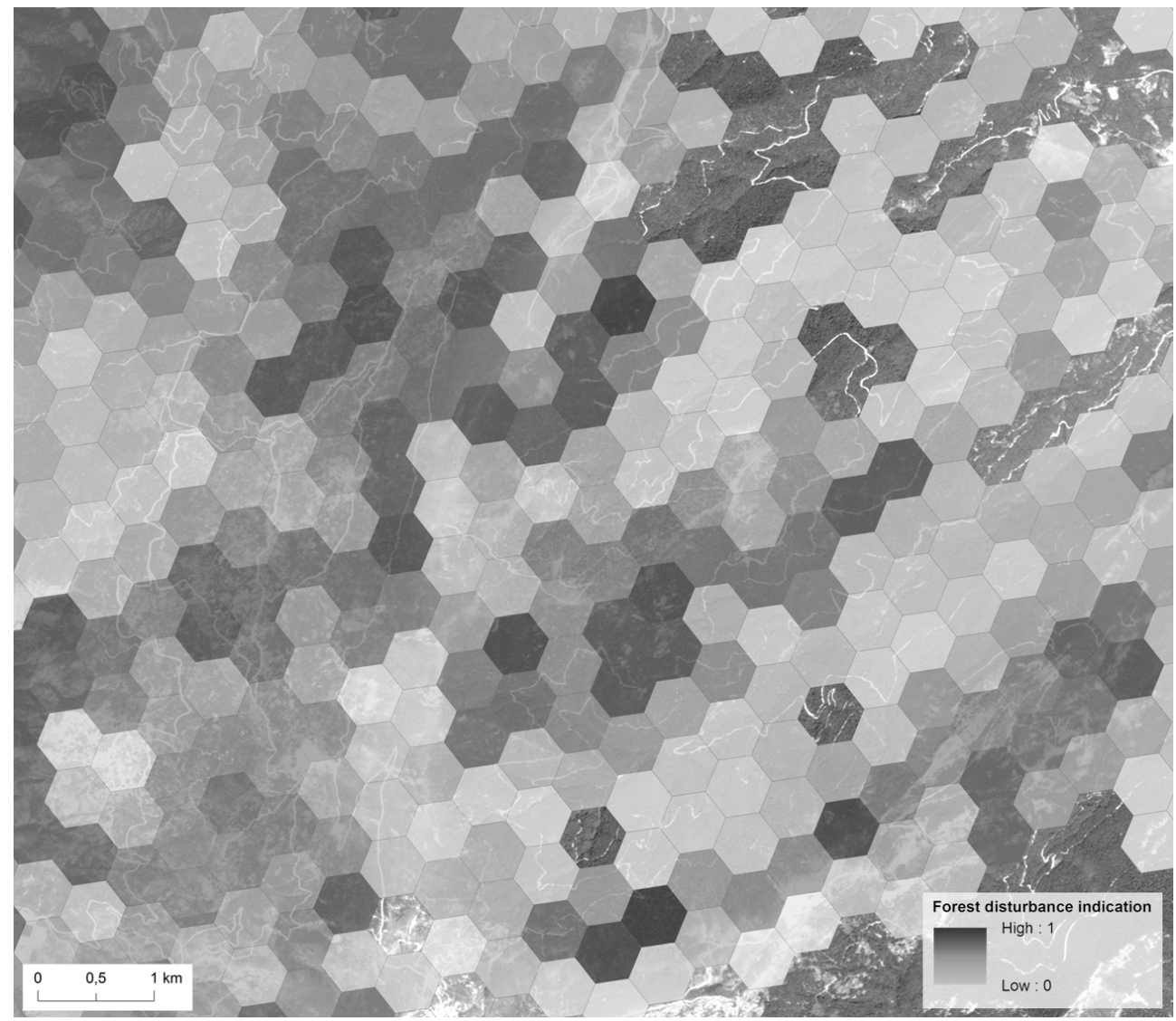

Fig. 1: Information layer on forest disturbance in Greece (subset; for full extent see http://www.ms-monina.eu/geoportal - Greek mountain coniferous forest: Forest disturbance probability - hexagon level).

\section{Fine-scale Monitoring of Riparian Forest Habitats}

EO data is not only useful for a broad-scale monitoring of forest quality attributes but also provides valuable information on a finer scale, i.e. on the level of individual protected sites. VHR satellite data and object-based class modelling enable fine-scaled, yet area-wide forest habitat mapping and monitoring (STRASSER et al. 2014). This was tested for riparian zones, which represent complex ecosystems that consist of biotic and abiotic functional elements. Riparian forest habitats are representative elements of riparian zones, accompanied by other elements such as aquatic habitat, river bed, intertidal zone and wetlands (NAIMAN 1997, TOCKNER \& STANFORD 2002, WARD et al. 2002). The delineated complex habitat classes can then be taken as a basis to assess the habitat quality of riparian forest with the help of suitable indicators (RIEDLER et al. 2013). 
Class modelling (TIEDE et al. 2010) is suitable for incorporating information on the structural composition of habitat systems, which are hierarchically organized and thus decomposable in their functional elements. A semi-automated approach (STRASSER et al. 2014, STRASSER et al. 2012) was set up for mapping riparian forest habitats in Europe by applying class modelling of EUNIS-3 (European Nature Information System, Level 3) (DAVIES 2004) habitats, and incorporating strategies for the transferability to different nature protected habitat sites as well as additional information. WorldView-2 satellite data with $0.5 \mathrm{~m} \mathrm{GSD}$ and 8 multispectral bands, covering the Natura 2000 site Salzach river floodplain (Austria), were used for a 3-level hierarchical representation of riparian forest habitats (Fig. 2). The levels represent different scale domains in a continuous scale spectrum. Based on an initial tree species classification level (-1) and composed forest stands (level 0 ), final habitats (level +1 ) were delineated by using a semantic model derived from the EUNIS classification scheme (STRASSER et al., 2014). The classification of forest stands, resulting in phyto-sociological units, was based on the tree species dominance.

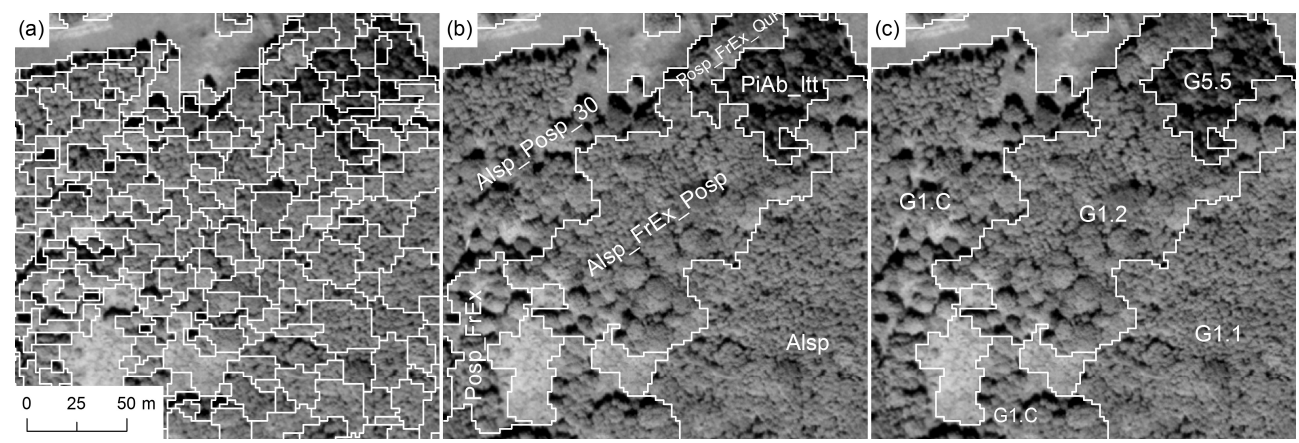

Fig. 2: Class modelling of riparian forest habitats from tree stands (a) to forest stands (b) and (c) final EUNIS-3 classes. Tree stand classification level consists of Alnus sp. (Alsp), Fraxinus excelsior (FrEx), Quercus robur (QuRo), Salix alba (SaAl), Populus sp. (Posp) and Picea abies (PiAb). Forest stands (b) were composed by the mixture of tree stand species. EUNIS-3 classes (c) were assigned according to the semantic model indicating the translation from forest stand habitats to EUNIS-3 classes.

The boundaries of the resulting EUNIS-3 classes were used to derive different indicators that contribute to an assessment of the habitat quality for each of these forest patches. In this context, we selected two indicators resulting from EO data that cover two aspects of riparian forest habitat quality: (1) the proportion of native key species revealing the naturalness of tree species composition, and (2) the variance in terrain roughness as the approximation for the flood regime. The proportion of native key tree species was directly obtained from the class modelling process (Fig. 2). Terrain roughness, defined as the standard deviation of slope per forest patch, was derived from a digital terrain model based on LiDAR data with $1 \mathrm{~m}$ GSD. For further EO-based indicators which are suitable to assess the quality of riparian forests refer to RIEDLER et al. (2013). A high variance in terrain roughness (Fig. 3b) indicates a water regime characteristic for riparian forests, which in turn favours the occurrence of typical native tree species (Fig. 3a). Both indicators reflect 
natural habitat conditions and thus a good conservation status of the respective forests (Fig. $3 \mathrm{~d})$. Areas with a low proportion of typical tree species or a low variance in terrain roughness on the other hand can also easily be identified (Fig. 3c). Measures to improve habitat quality like the logging of allochthonous trees and reforestation with autochthonous tree species, or the creation of ponds to increase soil wetness, can easily be planned using spatial mapping of the respective indicators. To facilitate the overall assessment of forest conservation status and compare different forest sites, the use of a composite indicator, which is composed of several sub-indicators, is recommended.

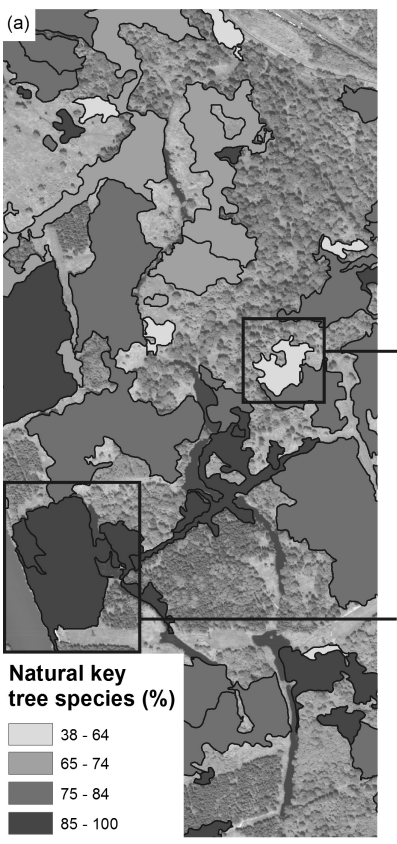

Indicators revealing poor forest quality

Natural key tree species $=38 \% \quad$ Terrain roughness $=2,3$

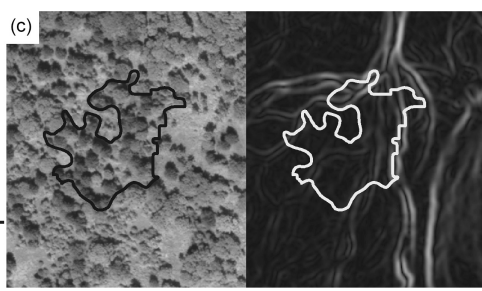

Indicators revealing good forest quality Natural key tree species $=85 \%$ Terrain roughness $=6,8$
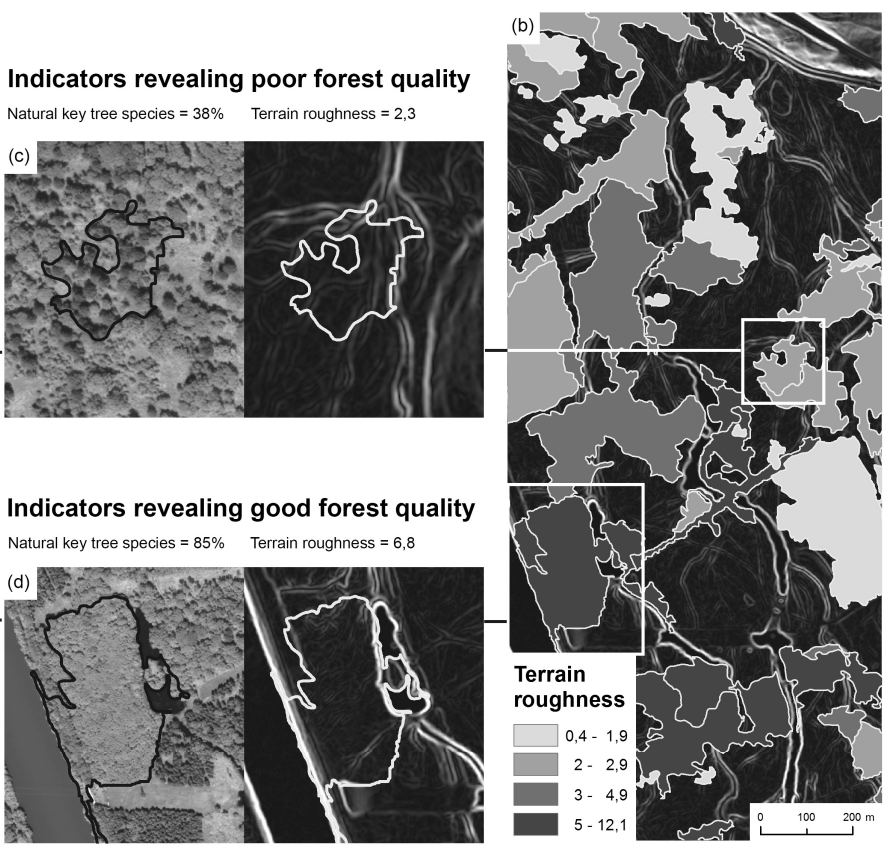

Fig. 3: Indicators describing the habitat quality of riparian forest at the Salzach river floodplain: (a) composition of native key species, and (b) terrain roughness. Details show forest patches with (c) poor forest quality, and (d) good forest quality.

\section{Summary and Outlook}

Satellite EO data are a viable source for standardized, repeatable and transferable multiscale forest monitoring. Information layers and indicators are designed for an easy understanding, and represent ready to use products for decision making, which facilitates sustainable forest management. Multi-scale monitoring provides information on different scales that can be used for general habitat quality assessment for area-wide observations, and finer scale evaluation, guiding local conservation management action. To capture the continuous behaviour of vegetation, different analysis levels of detail are required. In general, better results are obtained by the additional use of multi-temporal satellite data to 
cover the whole vegetation period of forest habitats. Therefore, the potential for long-term monitoring rose when methods were designed for temporal analysis. In particular, the monitoring of protected forest sites via EO and in combination with in-field verification is recommended, as protected sites are considered as hotspots for biodiversity conservation.

The presented indicators can provide information about the trends and changes in forest habitats distribution. Nevertheless, none of the indicator systems have been entirely accepted, and future research is necessary to develop new and specify current decisionmaking tools that can be applied in forest management.

\section{Acknowledgements}

This work was supported by the European Community's Seventh Framework Programme (FP7/2007-2013) under Grant Agreement 263479 [Multi-scale Service for Monitoring Natura 2000 Habitats of European Community (MS.MONINA)]. The research of Antonia Osberger is financed through a DOC-fFORTE-fellowship of the Austrian Academy of Sciences.

\section{References}

Birch, C. P. D., OOM, S. P. \& Beecham, J. A. (2007), Rectengular and hexagonal grids used for observation, experiment and simulation in ecology. Ecological mod., 206, 347359.

BLASCHKE, T. (2010), Object based image analysis for remote sensing. ISPRS International Journal of Photogrammetry and Remote Sensing, 65 (1), 2-16.

Buck, O., Klink, A., Virginia, E. G. M., Pakzad, K. \& Müterthies, A. (2013), Image Analysis Methods to Monitor Natura 2000 habitats at Regional Scales - the MS:MONINA State service Example in Schleswig-Hostein, Germany. Journal of Photogrammetry, Remote Sensing and Geoinformation Science, 2013 (5), 415-426.

CARr, D. B., Olsen, A. R. \& White, D. (1992), Hexagon mosaic maps for display of univariate and bivariate geographical data. Cartogr. Geo. Inform. Syst., 19, 228-236.

DATT, B. (1998), Remote Sensing of Chlorophyll a, Chlorophyll b, Chlorophyll a+b, and total Carotenoid Content in Eucalyptus Leaves. Remote Sensing of Env., 66, 111-121.

DAviEs, C. E., Moss, D. \& HILl, M. O. (2004), EUNIS Habitat Classification Revised 2004. http://eunis.eea.europa.eu/upload/EUNIS_2004_report.pdf.

Duro, D., CoOps, N. C., Wulder, M. A. \& Han, T. (2007), Development of a large area biodiversity monitoring system driven by remote sensing. Progress in Physical Geography, 31, 235-260.

GebureK, T., Milasowsky, N., Frank, G., Konrad, H. \& Schadauer, K. (2010), The Austrian Forest Biodiversity Index: All in one. Ecological Indicators, 10, 753-761.

Gitelson, A. (2004), Wide Dynamic Range Vegetation Index for Remote Quantification of Biophysical Characteristics of Vegetation. Journal of Plant Physi., 161 (2), 165-173.

LANG, S. (2008), Object-based image analysis for remote sensing applications: Modelling reality - dealing with complexity. In: BlaschKe, T., LANG, S. \& HAY, G. J. (Eds.), Object-Based Image Analysis - Spatial concepts for knowledge-driven remote sensing applications. Springer, Berlin, 3-27. 
Lang, S., Corbane C. \& Pernkopf L. (2013), Earth Observation for Habitat and Biodiversity Monitoring. In: LANG, S. \& PERNKOPF (Eds.), Ecosystem and biodiversity monitoring: best practice in Europe and globally (= GI-Forum 2013. Creating the GISociety), Vienna, Austrian Academy Press, 478-486.

MARCHETTI, M. (2004), Monitoring and Indicators of Forest Biodiversity in Europe - From Ideas to Operationality. EFI Proceedings, 51, $526 \mathrm{pp}$.

Meigs, G. W., Kennedy, R. E. \& Cohen, W. B. (2011), A Landsat time series approach to characterize bark beetle and defoliator impacts on tree mortality and surface fuels in conifer forests. Remote Sensing of Environment, 115, 3707-3718.

NAIMAN, R. J. \& DECAMPS, H. (1997), The Ecology of Interfaces: Riparian Zones. Annual Review of Ecology and Systematics, 28, 621-658.

Osberger, A. \& TIEDE, D. (2013), Forest Disturbance Information Layer for Alpine Forest Habitats. In: JEKEL, T. et al. (Eds.), GI_Forum 2013. Creating the GISociety. Vienna, Austrian Academy Press, 528-531.

Paletto, A., Ferretti, F., De Meo, I., Cantiani, P. \& Focacci, M. (2012), Ecological and Environmental Role of Deadwood in Managed and Unmanaged Forests. In: DIEZ, J. J. (Ed.), Sustainable Forest Management - Current Research, 219-238.

Riedler, B., Strasser, T., Pernkopf, L., Tiede, D., Lang, S. (2013), Habitat Quality Analysis of Natura 2000 Riparian Forests. In: LANG, S. \& PERNKOPF (Eds.), Ecosystem and biodiversity monitoring: best practice in Europe and globally (= GIForum 2013. Creating the GISociety), Vienna, Austrian Academy Press, 540-543.

Schuck, A., Meyer, P., Menke, N., Lier, M. \& Lindner, M. (2004), Forest biodiversity indicator: dead wood - a proposed approach towards operationalising the MCPFE indicator. EFI-Proceedings, 51, 49-77.

Strand, H., Höft, R., Strittholt, J., Miles, L., Horning, N., Fosnight, E. \& TURNER, W. (Eds.) (2007), Sourcebook on Remote Sensing and Biodiversity Indicators. Montreal: Secretariat of the Convention on Biological Diversity, No. 32.

Strasser, T., Lang, S., Riedler, B., Pernkopf, L. \&PACcagnel, K. (2014), Multiscale Object Feature Library for Habitat Quality Monitoring in Riparian Forests. Geoscience and Remote Sensing Letters, IEEE 11, 559-563.

Strasser, T., LANG, S., PernKopf, L. \& Paccagnel, K. (2012), Object-based class modeling for assessing habitat quality in riparian forests. In: GEOBIA 2012, Rio de Janeiro, Brazil, 555-560.

Tiede, D., LAng, S., Albrecht, F. \& Hölbling, D. (2010), Object-based class modeling for cadastre constrained delineation of geo-objects. Photogrammetric Engineering \& Remote Sensing, 193-202.

TOCKNER, K. \& STANFORD, J. A. (2002), Riverine flood plains: present state and future trends. Environmental Conservation, 29 (3), 308-330.

Vanden Borre, J., PaelinckX, D., Mücher, C. A., Kooistra, L., Haest, B., De Blust, G.\& SCHMIDT, A. M. (2011), Integrating remote sensing in Natura 2000 habitat monitoring: Prospects on the way forward. Journal for Nature Cons., 19, 116-125.

Ward, J. V., Tockner, K., Arscott, D. B. \& Claret, C. (2002), Riverine landscape diversity. Freshwater Biology, 47 (4), 517-539.

ZAWIŁA-NIEDŹWIECKI, T., IRACKA, M. \& WiŚNIEWSKA, E. (2000), Case study: Monitoring of degraded mountain forests in Central Europe using remote sensing. In: PRICE, M. F. \& ButT, N. (Eds.), Forests in Sustainable Mountain Development: A State of Knowledge Report for 2000. IUFRO 5 Research Series, CABI Publishing, 13-18. 